\title{
O comportamento populacional e os focos de calor ativo no Setor Lagoa da Ilha
}

O bairro Setor Lagoa da llha é o de maior registro de queimas, queimadas e incêndios florestais do município tocantinense de Lagoa da Confusão, o qual se localiza na microrregião sudoeste com o terceiro maior território estadual, possui população superior a 10.000 habitantes, base econômica na agropecuária, elevada arborização nas vias públicas, e, apresenta o maior registro de focos de calor ativos na série histórica de 2009 a 2018. Em verificação complementar, este município possui a segunda menor taxa de escolarização do estado e o maior PIB Agropecuário, cujo PIB per capita é superior a R\$39.000,00, e, frente a estas controversas realidades os pesquisadores delimitaram como objetivo compreender o comportamento populacional dos habitantes deste bairro, que é o recorte territorial desta pesquisa. A metodologia é de caráter quali-quantitativo com uso da pesquisa bibliográfica e análise documental para subsídio do caráter qualitativo, enquanto o caráter quantitativo se deu na pesquisa de campo com aplicação do instrumento de pesquisa um questionário de abordagem ecocultural para a coleta de dados, e a interpretação destes dados ocorreu por meio de análise quantitativa proporcional à amostragem obtida, com exceção dos respondentes que alcançaram algum dos critérios de exclusão. $\mathrm{O}$ questionário foi composto por onze variáveis, das quais nove foram empregadas nesta pesquisa, e anterior à sua aplicação foi obtida a prévia autorização do Comitê de Ética em Pesquisas em Seres Humanos da Universidade Federal do Tocantins. Ao final deste estudo, concluiu-se que o objetivo proposto foi de caráter total, pois o comportamento populacional do Setor Lagoa da Ilha do município tocantinense de Lagoa da Confusão foi compreendido.

Palavras-chave: Queimas; Focos de calor; Lagoa da Confusão; Incêndios florestais.

\section{The populational behavior and the active hotspots in the Lagoa da Ilha District}

\begin{abstract}
The Setor Lagoa da llha district is the larger register of burns, burned and wildfires of Tocantins county Lagoa da Confusão, which is located at the south-west microregion with the third largest state territory, it has a population over than 10,000 inhabitant, economic base in agriculture, high afforest at thoroughfare, and, shows the record of active hotspots at the historic series of 2009-2018. In complementary verification, this county has the second worst state schooling rate and the better Agriculture PIB, whose PIB per capita is greater than 39,000.00, and, in front of this reality controversial the researches defined the objetctive comprehend the populational behavior of the district residentes, that is the territorial profile of this search. The metodology is the quail-quantitative with the use of bibliographic search and documental analysis to qualitative character subsidy, while the quantitative character happens in field research the with aplication of search a tool questionary of ecocultural approach for the data collect, and the interpretation of these occurred throughquantitative analysys proportional to sampling obtained, except of respondentes that reached some exclusion criteria. The questionary was composed of eleven variables, of which nine were used in this search, and previous to your application was obtained the prior authorization from the Comitê de Ética em Pesquisas em Seres Humanos of the Universidade Federal do Tocantins. At end of this study, concludes that the proposed objective was total character, because the populational behavior of Setor Lagoa da Ilha of Tocantins county Lagoa da Confusão as comprehended.
\end{abstract}

Keywords: Burns; Hotspots; Lagoa da Confusão; Wildfires.

Topic: Desenvolvimento, Sustentabilidade e Meio Ambiente

Reviewed anonymously in the process of blind peer.
Received: 05/10/2020

Approved: $26 / 11 / 2020$
Cléber José Borges Sobrinho

Universidade Federal do Tocantins, Brasil http://lattes.cnpq.br/2925929082473530 http://orcid.org/0000-0001-7356-9116

cleberborgess@yahoo.com.br

Dernival Venâncio Ramos Júnior (iD

Universidade Federal do Tocantins, Brasil

http://lattes.cnpq.br/9941464654933458

http://orcid.org/0000-0001-5092-1199

dernivaljunior@gmail.com

\section{Referencing this:}

BORGES SOBRINHO, C. J.; RAMOS JÚNIOR, D. V.. O comportamento populacional e os focos de calor ativo no Setor Lagoa da Ilha. Revista Ibero Americana de Ciências Ambientais, v.11, n.6, p.510-521, 2020. DOI: http://doi.org/10.6008/CBPC2179-6858.2020.006.0041 


\section{INTRODUÇÃO}

O município de Lagoa da Confusão possui a terceira maior área territorial do Estado do Tocantins, com 10.564,683 km², está localizado na microrregião sudoeste, com mais de $88 \%$ das vias públicas arborizadas, e seu registro populacional, segundo o Censo Brasil de 2010, apontava uma população de 10.210, contudo sua estimativa para 2019 possui registro de 13.357 habitantes (LAGOA DA CONFUSÃO, 2018; IBGE, 2020a).

A principal base econômica lagoense é a agropecuária, com o maior PIB per capita do Tocantins em valor superior a $\mathrm{R} \$ 39.000,00$, enquanto o salário médio mensal por trabalhador formal é superior a dois salários mínimos, o que o classifica como o quarto melhor no Tocantins; estes índices são inversamente proporcionais com os dados educacionais, uma vez que a taxa de escolarização básica ${ }^{1}$ é de $88,5 \%$, sendo a segunda pior do Estado (IBGE, 2020a).

Segundo Borges Sobrinho et al. (2020a), dentre os 139 municípios tocantinenses, Lagoa da Confusão alcançou o maior quantitativo de incidências registradas na série histórica compreendida entre os anos de 2009 a 2018, com mais de 12.000 focos de calor ativo ${ }^{2}$ listados, não obstante, estes focos de calor são compreendidos como qualquer ponto verificado via sensoriamento remoto a uma temperatura registrada acima de $47^{\circ} \mathrm{C}$, e não devem ser confundidos com as queimadas, que segundo Santos (2018) se trata de uma ferramenta planejada para limpeza, renovação e transformação de pastagens, e nem confundidos com os incêndios florestais os quais configuram uma ação do fogo sem o controle humano que resulta em danos às espécies vegetativas, alteração comportamental de ecossistemas, queima da biomassa, liberação de gases tóxicos, etc. (CBMGO, 2017).

Em Lagoa da Confusão há frentes preventivas e reativas ao combate às queimadas e incêndios florestais desde o ano de 2012 por meio da formação de brigadas florestais, as quais são capacitadas em parcerias com o Instituto Brasileiro do Meio Ambiente e Recursos Naturais Renováveis - IBAMA, com a Secretaria Estadual do Meio Ambiente e Recursos Hídricos - SEMARH, e, cujo ponto de máximo de queima deste município é o bairro denominado Setor Lagoa da Ilha, o qual apresenta o maior quantitativo de queimas e queimadas registradas pela Secretaria Municipal de Meio Ambiente e Segurança Pública (LAGOA DA CONFUSÃO, 2019).

Vale apontar que Lagoa da Confusão é um dos municípios tocantinenses que integra o Protocolo do Fogo, e por meio de parcerias busca capacitar brigadistas florestais indígenas, fornece alimentação, materiais, combustível e equipamentos de proteção individual para as equipes atuantes no combate às queimadas e aos incêndios florestais (LAGOA DA CONFUSÃO, 2019).

Destaca-se que o Protocolo do Fogo consiste nas normativas desenvolvidas pelo Comitê do Fogo ${ }^{3}$ para fins de estudos e elaboração de um plano de ações anual com a participação de diversas organizações

\footnotetext{
${ }^{1}$ Refere-se à idade escolar de seis a catorze anos (IBGE, 2020).

2 "Os focos de calor são monitorados pelo Centro de Pesquisa do Tempo e Estudos Climáticos (CPTEC) do Instituto Nacional de Pesquisas Espaciais (INPE) através da análise das imagens de diferentes satélites (das séries NOAA, GOES, AQUA, TERRA e METEOSAT) que rastreiam a superfície terrestre diariamente ou várias vezes por dia" <http://www.seia.ba.gov.br/monitoramento-ambiental/focos-de-calor>.

${ }^{3}$ BORGES SOBRINHO et al. (2020b); CEPDEC (2019).
} 
públicas e privadas, por meio do qual há o direcionamento para políticas públicas de educação, prevenção e controle de queimadas e incêndios florestais no Estado do Tocantins (CEPDEC, 2019).

Nesta perspectiva, este estudo objetiva compreender o comportamento populacional dos habitantes do Setor Lagoa da Ilha do município tocantinense de Lagoa da Confusão diante das queimas, queimadas e incêndios florestais, por meio da aplicação de um questionário autorizado pelo Comitê de Ética em Pesquisa em Seres Humanos - CEP, da Universidade Federal do Tocantins - UFT. Como consequência, esta pesquisa se justificativa, uma vez que de posse dos diferentes comportamentos ecoculturais é possível revisar e estabelecer novas metodologias preventivas e reativas no combate às queimas, queimadas e aos incêndios florestais no território já delimitado.

\section{REVISÃO TEÓRICA}

O Estado do Tocantins é composto em sua quase totalidade pela vegetação de cerrado, possui clima tropical, recursos hídricos favoráveis à produção de energia elétrica e agrossistemas e ciclagem de nutrientes do solo vinculada a processos de decomposição; suas características geomorfológicas e climatológicas são favoráveis às incidências de queimadas e incêndios florestais, e, com uma prática ecocultural de limpeza de pastos e modificação de áreas de pastagens, as queimas também são ações de rotina (IBGE, 2019; TOCANTINS, 2015).

Segundo Borges Sobrinho et al. (2020a), as queimadas e incêndios florestais no Estado do Tocantins estão presentes em todos os meses do ano, com as incidências de queima distribuídas em dois períodos climatológicos, no qual o primeiro é uma estiagem que inicia em junho e finaliza em novembro, e o segundo período, o chuvoso, inicia em dezembro e vai até maio. O ponto de máximo dos focos de calor ativo está no mês de setembro, enquanto o ponto de mínimo se encontra no mês de fevereiro.

Em compreensão a esta sazonalidade do Estado do Tocantins, as queimadas e os incêndios florestais proporcionam uma queima intensa no período de estiagem, e em consonância as duas variáveis de área vegetativa propícia à queima e estado pouco populoso, há maior probabilidade para combustão e conflagração tanto das queimas, das queimadas quanto dos incêndios florestais (BORGES SOBRINHO et al., 2020b).

E em referência ao quantitativo registrado dos focos de calor ativo no Estado Tocantins, e em recorte ao município de Lagoa da Confusão, o qual é o de maior registro destes índices, o Produto Interno Bruto PIB Agropecuário deve ser afetado por queda ou por força, uma vez que se trata de um município com grande área territorial e com o maior PIB per capita tocantinense, mesmo com segunda pior colocação estadual em taxa de escolarização básica (LAGOA DA CONFUSÃO, 2018; IBGE, 2020a).

Portanto, para esta compreensão mensura-se o quantitativo em nível de amostra em população é referente a todos os 139 municípios tocantinenses na condição de variável quantitativa discreta, para uma análise amostral finita o índice de confiança adotado para a pesquisa foi o de $90 \%$, cujo desvio padrão é de 1,645, em uma margem de erro máximo de 15\%, para a distribuição de uma população mais homogênea. Por meio da Fórmula de Cálculo Amostral, a amostragem resultou em 18 municípios, que foram dispostos na 
seguinte ordem decrescente:

Tabela 1: Variável \# 5938 - Participação do valor adicionado bruto a preços correntes da agropecuária por municípios do Estado do Tocantins em porcentagem (\%)

\begin{tabular}{|l|l|l|l|l|l|l|l|l|}
\hline \multirow{2}{*}{$\#$} & \multirow{2}{*}{ Município } & \multicolumn{2}{|l|}{ Ano } & \multicolumn{1}{l|}{ Acúmulo } \\
\cline { 3 - 8 } & & 2010 & 2011 & 2012 & 2013 & 2014 & 2015 & \\
\hline 1 & Lagoa da Confusão (TO) & 4,49 & 3,83 & 3,19 & 5,21 & 6,58 & 5,29 & 4,765 \\
2 & Pedro Afonso (TO) & 2,51 & 6,28 & 4,90 & 6,07 & 3,31 & 3,84 & 4,485 \\
3 & Campos Lindos (TO) & 3,94 & 3,77 & 4,76 & 4,52 & 5,02 & 3,83 & 4,307 \\
4 & Formoso do Araguaia (TO) & 3,92 & 3,82 & 3,78 & 4,65 & 3,52 & 3,70 & 3,898 \\
5 & Dianópolis (TO) & 5,62 & 4,69 & 4,88 & 3,44 & 3,96 & 0,47 & 3,843 \\
6 & Porto Nacional (TO) & 2,03 & 4,85 & 4,77 & 2,43 & 2,81 & 3,08 & 3,328 \\
7 & Mateiros (TO) & 1,74 & 2,52 & 2,22 & 3,17 & 3,68 & 2,05 & 2,563 \\
8 & Peixe (TO) & 1,75 & 1,34 & 1,81 & 1,50 & 1,95 & 2,92 & 1,878 \\
9 & Dueré (TO) & 1,74 & 1,80 & 1,61 & 1,50 & 1,62 & 2,16 & 1,738 \\
10 & Araguaçu (TO) & 1,81 & 1,74 & 1,64 & 1,62 & 1,61 & 1,94 & 1,727 \\
11 & Arraias (TO) & 3,06 & 1,72 & 1,57 & 1,69 & 0,94 & 0,99 & 1,662 \\
12 & Araguaína (TO) & 2,01 & 1,70 & 1,60 & 1,37 & 1,45 & 1,61 & 1,623 \\
13 & Palmas (TO) & 1,13 & 1,68 & 1,68 & 1,59 & 1,79 & 1,45 & 1,553 \\
14 & Monte do Carmo (TO) & 1,33 & 1,40 & 1,33 & 1,21 & 1,89 & 1,76 & 1,487 \\
15 & Almas (TO) & 1,41 & 1,34 & 1,41 & 1,37 & 1,49 & 1,73 & 1,458 \\
16 & Alvorada (TO) & 0,88 & 0,98 & 1,58 & 1,63 & 1,79 & 1,52 & 1,397 \\
17 & Guaraí (TO) & 1,68 & 1,35 & 1,38 & 1,24 & 1,21 & 1,06 & 1,320 \\
18 & Pium (TO) & 1,27 & 1,19 & 1,35 & 1,09 & 1,35 & 1,61 & 1,310 \\
\hline
\end{tabular}

Fonte: IBGE (2017).
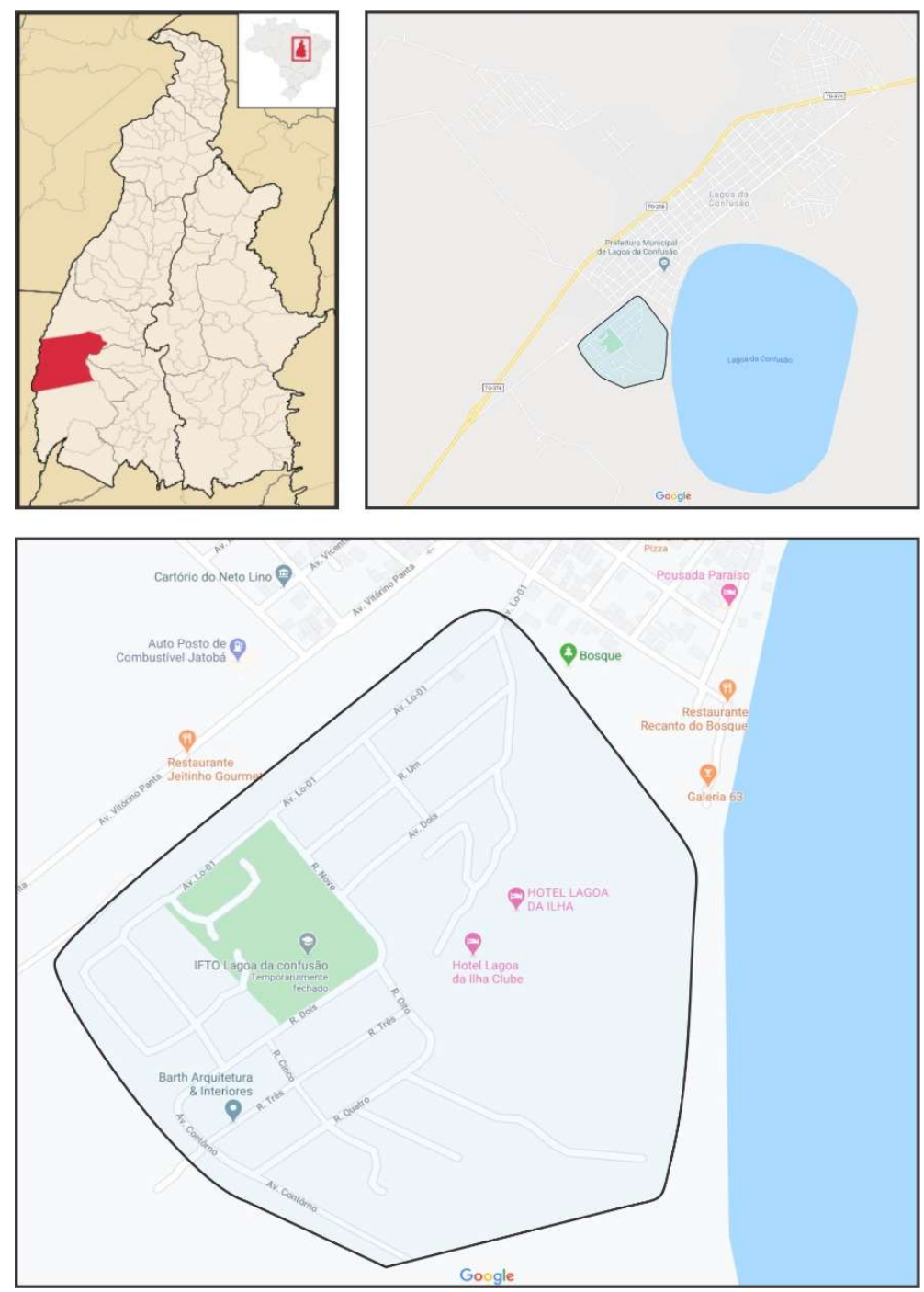

Imagem 1: Perspectiva situacional do bairro Setor Lagoa da Ilha.

Compreende-se da tabela acima que o município tocantinense de maior registro da série histórica de 
focos de calor ativo apresenta o maior PIB Agropecuário estadual acumulado no período de 2010 a 2015, portanto, a variável educacional não justifica os índices financeiros registrados pelo IBGE, e, como há índices contraditórios a pesquisa de campo se torna um instrumento válido a ser aplicado, com o respectivo recorte territorial, que para esta pesquisa será o Setor Lagoa da Ilha, o bairro de maior registro histórico de queimas, queimadas e incêndios florestais do município de Lagoa da Confusão. Segue abaixo a perspectiva situacional do referido recorte territorial:

Este bairro se localiza na região sudoeste lagoense e possui sua maior ocupação territorial por lotes lindeiros abertos, sua pavimentação asfáltica está presente em menos da metade do espaço urbano, possui pontos de arborização em todas as ruas com a presença de capim andropogon e de vegetação nativa de cerrado. Estes apontamentos justificam os elevados índices de queima, tanto em nível da quantidade de material de carga incendiária como em área a ser queimada. Para visualização e compreensão do descrito segue um mosaico de imagens do recorte territorial em estudo:

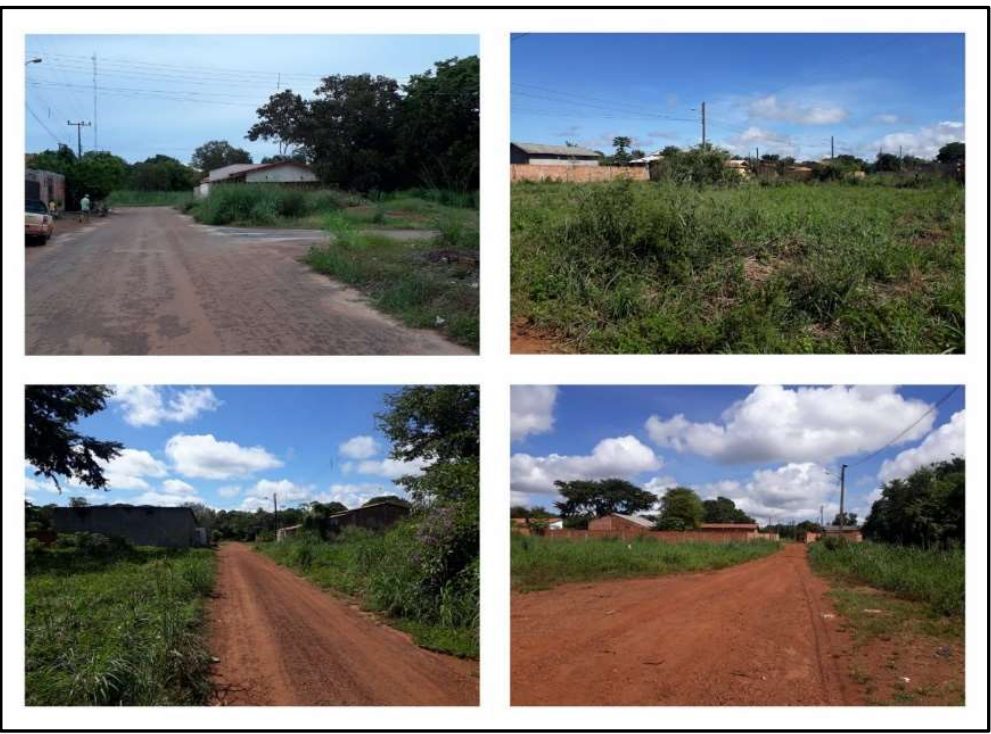

Imagem 2: Mosaico de imagens do bairro Setor Lagoa da Ilha.

Segundo IBGE (2020b), o bairro Setor Lagoa da Ilha possui uma configuração ocupacional e habitacional total de 117 espécies, conforme distribuição abaixo disposta:

Quadro 1: Espécie Habitação do Setor lagoa da Ilha do município tocantinense de Lagoa da Confusão.

\begin{tabular}{|l|l|l|l|}
\hline Ordem & Espécie & Tipo & Quantitativo \\
\hline 01 & Estabelecimento de ensino & Educacional & 02 \\
\hline 02 & Estabelecimento de outras finalidades & Mercado, Bares, Vendas, Outros & 01 \\
\hline 03 & Edificação em construção & Construção & 12 \\
\hline 04 & Estabelecimento religioso & Igreja & 01 \\
\hline 05 & Domićlio coletivo sem morador & Hotel, Pensão e Similares & 01 \\
\hline 06 & Domicílio particular permanente ocupado & Casa / Moradia & 22 \\
\hline 07 & Domicílio particular permanente fechado & Casa / Moradia & 66 \\
\hline 08 & Domicílio particular permanente uso ocasional & Casa / Moradia & 01 \\
\hline 09 & Domicílio particular permanente vago & Casa / Moradia & 11 \\
\hline
\end{tabular}

Fonte: IBGE (2020b).

Dentre todas espécies existentes, os pesquisadores tinham por alvo os domicílios 'particular permanentemente ocupado' e 'particular permanentemente fechado', portanto, uma possibilidade máxima 
de aplicação de 88 questionários; uma vez que para fins de compreensão do fenômeno de queimas, queimadas e incêndios florestais havia a necessidade de aplicação de questionário aos moradores do bairro Lagoa da Ilha. Os índices comparativos, bem como o levantamento, a análise e a compreensão serão apresentados em capítulo específico.

\section{METODOLOGIA}

Esta pesquisa está subsidiada por produções científicas interdisciplinares que referenciem o comportamento populacional dos moradores do Setor Lagoa da llha do município tocantinense de Lagoa da Confusão quanto às práticas das queimas, queimadas e incêndios florestais com abordagens qualitativas para as discussões teóricas, e, abordagens quantitativas, por meio da aplicação de questionário aprovado pelo CEP da UFT, para compreensão dos fenômenos de queima.

Segundo Creswell (2010), um estudo apresenta caráter quali-quantitativo quando há possibilidade de diferentes estratégias de investigação seguidas de compreensões multidisciplinares para um fenômeno específico, e há indicação para pesquisa bibliográfica e análise documental no que consta o caráter qualitativo, e a disposição de gráficos, quadros e/ou tabelas para o caráter quantitativo.

Quanto ao objetivo e à justificativa que subsidiam esta pesquisa, há presença da pesquisa de campo, uma vez que o pesquisador atuou in loco por meio da aplicação do instrumento de questionário individual na condição de uma ferramenta composta por perguntas diretas e em múltipla escolha ofertadas a população pesquisada, por meio das quais se apresentou onze variáveis, das quais nove corroboram esta pesquisa (FGF, 2010).

As variáveis relacionavam informações de cunho pessoal dos sujeitos a serem pesquisados, como: sexo, etnia, idade, renda individual, nível de escolaridade, tempo de residência no bairro, observação periódica de queimas, prática presente e/ou passada de queimas, motivação para queima, intenção de concessão de entrevista, e, intenção de participação em brigada de incêndio florestal.

Por conter questionamentos pessoais houve a submissão ao CEP $^{4}$ da UFT, sob CAEE no 24786419.0.0000.5519, tendo por Instituição proponente a Fundação Universidade Federal do Tocantins, com financiamento próprio do pesquisador, e Parecer Consubstanciado aprovado no 3.853.151, sem a necessidade de aprovação da Comissão Nacional de Ética em Pesquisa - CONEP, com data de registro em 21 de fevereiro de 2020 .

Destaca-se que a identidade dos participantes e suas informações são preservadas, pois a privacidade, o sigilo e a confidencialidade são ações de efetivação para esta pesquisa. Logo, ao responder o questionário, o participante teve liberdade temporal para demandar quanto tempo julgasse necessário para resposta de cada variável, bem como houve liberdade para mudança de respostas já marcadas e desistência a qualquer momento, mesmo após finalização da aplicação do questionário; estes instrumentos foram aplicados pessoalmente, em via física, nos dias 18 e 19 de abril de 2020, com prévia explanação por parte do

\footnotetext{
${ }^{4}$ As informações aqui prestadas podem ser confirmadas pelo fone 63-3232-8023, email < cep_uft@uft.edu.br >, sito à Quadra 109 Norte, Avenida NS-15, Campus de Palmas, Prédio do Almoxarifado, CEP 77.001-090.
} 
pesquisador quanto ao Termo de Consentimento Livre e Esclarecido - TCLE, e somente após o aceite do respondente, o questionário era aplicado.

Foram listados quatro critérios de exclusão de participantes da pesquisa, sendo o primeiro por motivação ética, uma vez que as situações de fragilidade da saúde física, mental ou emocional bem como àqueles que estiverem sob acompanhamento médico ou sob licenças de saúde pessoais, como cuidados de familiares ou terceiros, ou ainda em período de luto não comporão o rol de participantes da pesquisa; o segundo critério de exclusão foi eletivo, já que a inclusão de cada participantes se deu por meio de ação voluntária ao limite de uma participação por residência, logo, em caso de não haver interesse na participação, a qualquer momento da pesquisa, haverá exclusão do participante na pesquisa; o terceiro critério se relaciona a idade do participante, o qual deverá ser adulto, logo, crianças e adolescentes não responderão o questionário; e, por fim, o último critério de exclusão envolve um quesito temporal de residência no lócus da pesquisa, pois o participante que informar que reside no Setor Lagoa da llha em período inferior a dois anos não terá a participação validada.

Destaca-se que para esta pesquisa os critérios de exclusão objetivam atender a Resolução № 466 do Conselho Nacional de Saúde, de 12 de dezembro de 2012, e, a Resolução № 510 do Conselho Nacional de Saúde, de 07 de abril de 2016, além do objetivo de compreensão do comportamento populacional proposto para esta pesquisa.

\section{RESULTADOS E DISCUSSÃO}

Em uma análise comparativa, a somatória do "domicílio particular permanentemente ocupado" com o "domicílio particular permanentemente fechado" resultou em uma População de 88, e durante a aplicação dos questionários, para os quais havia a limitação de um respondente por domicílio, foram localizados e aplicados em todos da primeira espécie, e localizados todos da segunda espécie, contudo com aplicação de 21/66 destes, uma vez que não foram encontrados os outros 45 habitantes destas espécies nos dias da pesquisa. A saber, o resultado é apresentado no quadro abaixo:

Quadro 2: Comparativo População-Amostragem: IBGE X Pesquisador.

\begin{tabular}{|l|l|l|l|l|}
\hline Ordem & Espécie & Quantitativo IBGE & Quantitativo Pesquisador & Comparativo \\
\hline 01 & Domicílio particular permanente ocupado & 22 & 22 & $100 \%$ \\
\hline 02 & Domicílio particular permanente fechado & 66 & 21 & $31,82 \%$ \\
\hline 03 & TOTAL & 88 & 43 & $48,86 \%$ \\
\hline
\end{tabular}

Em análise da Amostragem, a qual correspondeu 48,86\% da População, a primeira a variável, sexo, foi uma frequência semelhante, com 22 homens e 21 mulheres, contudo, em obediência aos critérios de exclusão, quatro homens e nove mulheres afirmaram residir no Setor Lagoa da Ilha em período inferior a dois anos, em consequência, 30 questionários foram validados, com 18 homens e 12 mulheres.

As demais variáveis de etnia, idade, renda individual, escolaridade, tempo de residência no bairro, observação periódica de queimas, prática presente e/ou passada de queimas, motivação para queima, intenção de concessão de entrevista, e, intenção de participação em brigada de incêndio florestal, estão abaixo dispostas a um número real total de 30. 
A segunda variável, etnia, apontou a percepção do próprio entrevistado quanto à sua compreensão, ao que não houveram respostas às etnias indígena e amarelo, contudo, brancos, pardos e negros foram apontados, com maioria de pardos, e seguiram na proporção disposta no gráfico 1.

A terceira variável foi a idade, por meio da qual o público-alvo foi dividido em seis grupos na taxa média a cada dez anos, com início aos 18 anos e possibilidade de classificação limite ao grupo "acima de 70 anos", para o qual não houve respondente. Dentre os demais participantes a proporção alcançada está descrito no gráfico 2 .

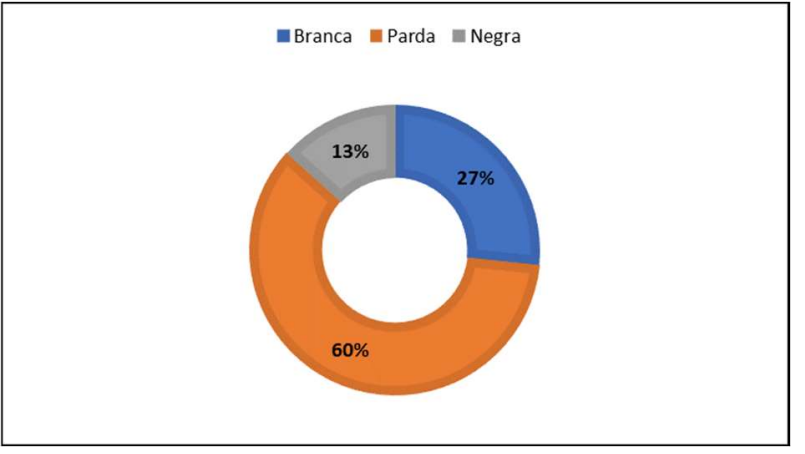

Gráfico 1: Etnias da amostragem pesquisada.

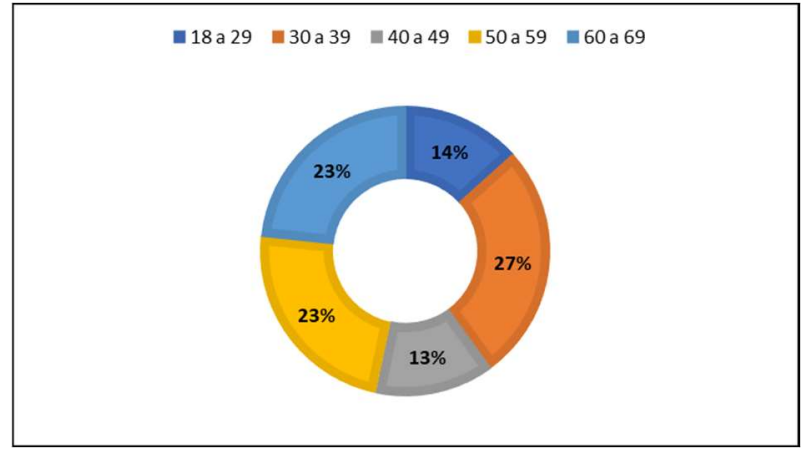

Gráfico 2: Grupos de idade da amostragem pesquisada.

Observa-se que os grupos de 18 a 29 anos e 40 a 49 anos possuem frequência semelhante, assim como os grupos de 50 a 59 anos e 60 a 69 anos, ao resta uma pequena maioria para o grupo de 30 a 39 anos.

A quarta variável, a qual se refere à renda individual, foi dividida em oito grupos, e os intervalos financeiros de $R \$ 7.500,00$ a $R \$ 9.999,99, R \$ R \$ 15.000,00$ a $R \$ 19.999,99$, e, acima de $R \$ 20.000,00$ não houve respondentes. Dentre os demais grupos o destaque se concentrou no grupo de menor valor, até R\$ $1.000,00$, o qual é inferior à média municipal ${ }^{5}$ (gráfico 3).

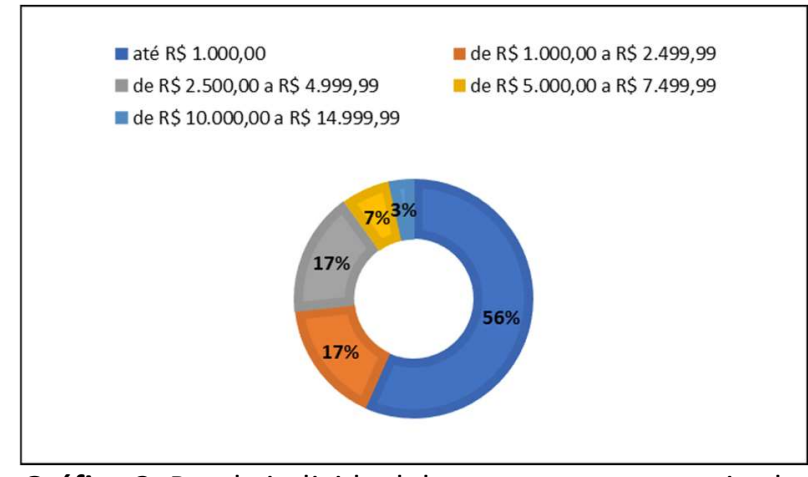

Gráfico 3: Renda individual da amostragem pesquisada.

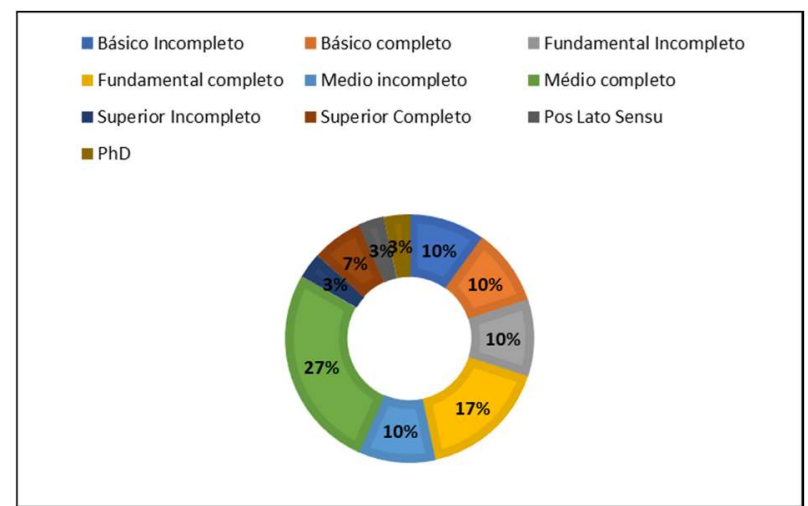

Gráfico 4: Escolaridade da amostragem pesquisada.

A variável escolaridade foi a quinta a ser pesquisada e a de maior divisão grupal, com doze possibilidades de resposta, contudo não houve apontamento para Mestrado e o único apontamento de Doutorado foi removido por critério de exclusão. Dentre as participações válidas, o grupo dos concluintes do Ensino Médio foram a maioria, e em conjunto aos demais ficaram assim dispostos no gráfico 4.

A sexta variável, composta por seis grupos, se refere ao tempo de residência do respondente no Setor

\footnotetext{
${ }^{5}$ Segundo IBGE (2020a) a renda média mensal da população de Lagoa da Confusão é de 2,2 salários mínimos. 
Lagoa da Ilha, e àqueles que responderam a alternativa 'há menos de 2 anos' foram excluídos, por considerar que o tempo de residência no território da pesquisa era insuficiente para correlacionar com as variáveis seguintes; o grupo cuja alternativa era 'Desde que nasci' não alcançou resposta, contudo para os demais grupos o resultado foi no gráfico 5 .

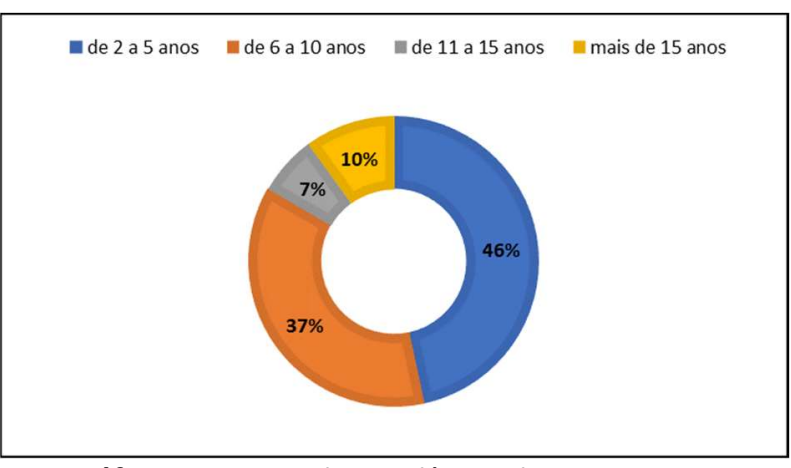

Gráfico 5: Tempo de residência da amostragem pesquisada.

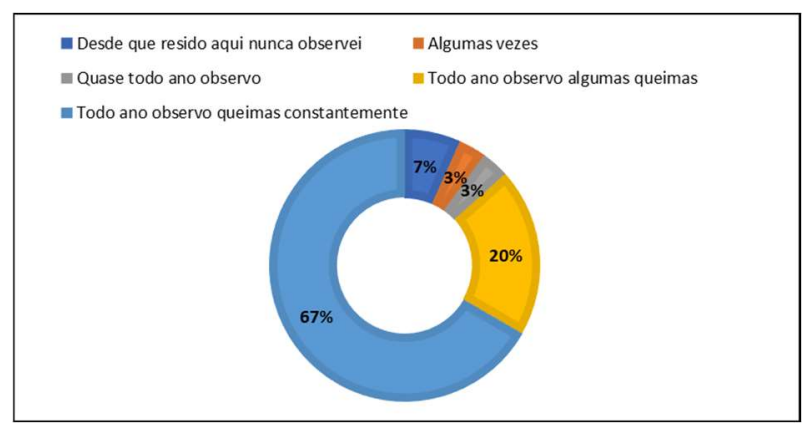

Gráfico 6: Observação da frequência de queimas da amostragem pesquisada.

Os respondentes também participaram quanto à observação da frequência de queimas no território em análise, sendo esta sétima variável composta por cinco grupos, aos quais todos receberam pelo menos um apontamento, e a maioria apontou que as queimas são observadas de forma constante todos os anos desde que residem no Setor Lagoa da Ilha (gráfico 6).

A oitava variável se referenciou à prática presente e/ou passada de queimas por parte dos respondentes, ao que todos os quatro grupos receberam apontamentos, o que variou de quem nunca realizou queimas a quem já realizou e ainda realiza. O contraditório se encontra nos respondentes que praticaram algumas vezes, mas que estão dispostos a novas práticas, enquanto outro grupo que também já praticou queimas e expõe que não possuem a intenção de realizar novas queimas. As proporções estão dispostas no gráfico 7.

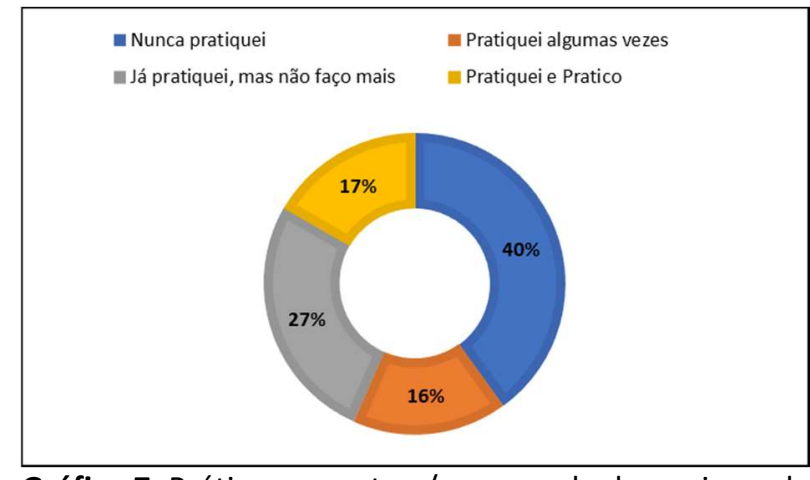

Gráfico 7: Prática presente e/ou passada de queimas da amostragem pesquisada.

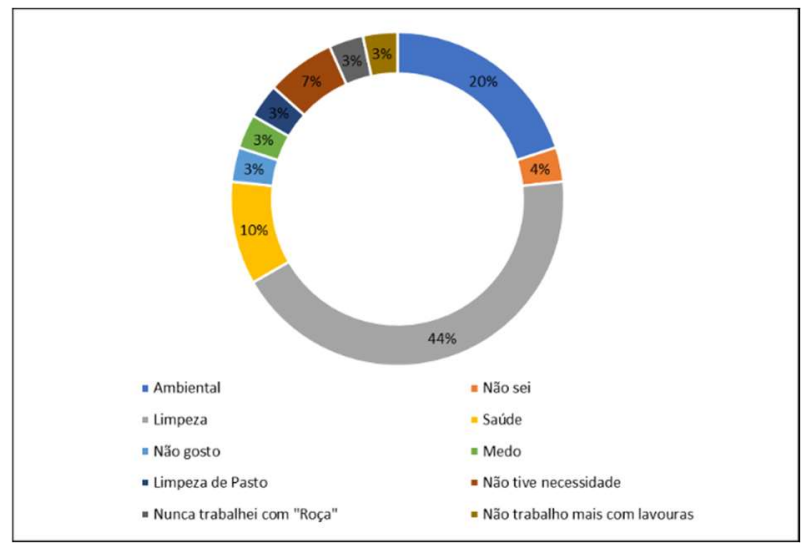

Gráfico 8: Motivação para prática de queimas da amostragem pesquisada.

A última variável válida para esta pesquisa buscou compreender qual a motivação de queima por parte dos respondentes por meio dos cinco seguintes grupos: Ambiental, Tradição, Religioso, Não sei responder, e, Outros. Os grupos Tradição e Religioso não obtiveram apontamento, contudo o grupo Outros foi subdividido, em virtude da diversidade das respostas dos respondentes, em oito grupos complementares. 
Foram inseridos os seguintes grupos: Limpeza, Saúde, Não gosto, Medo, Limpeza de pasto, Não tive necessidade, Nunca trabalhei com 'roça', e, Não trabalho mais com lavouras. Vale mencionar que dentre os questionários não-validados por critérios de exclusão, o grupo Outros ainda foi escolhido para afirmação de outras três subdivisões: Há outras ferramentas, Vizinhos, e, não tenho o que queimar.

Logo, dentre as participações válidas, no que se refere à oitava variável, houve o resultado de dez grupos, e mesmo com esta quantidade considerada elevada em comparativo as demais variáveis, dois grupos se destacaram como as principais justificativas que os respondentes do bairro de maior índice de queima do município tocantinense que mais queima: em primeiro a prática de queima para limpeza e em segundo a motivação ambiental. Para melhor compreensão deste contexto segue o gráfico 8 .

Portanto, mesmo com as motivações levantadas pelo pesquisador somadas as diferentes justificativas inseridas pelos respondentes, a queima para limpeza apresentou o maior quantitativo, e esta prática, segundo Torres et al. (2016) possui uma especificidade dicotômica por ser classificada como cultural e ao mesmo tempo ser a maior responsável por registros de ocorrências de incêndios florestais.

Diante da exposição dos resultados analisados das nove variáveis, vale destacar que as últimas duas variáveis existentes no questionário, a de intenção de concessão de entrevista, e, a de intenção de participação em brigada de incêndio florestal, não tiveram suas respostas listadas nesta pesquisa por não contribuir com esta etapa, uma vez que a décima variável conduz os respondentes a uma entrevista, que se trata de um instrumento para filtrar os respondentes interessados em apresentar os saberes ecoculturais quanto às queimas e queimadas, e, a décima primeira variável oportuniza aos interessados a participação em um curso de formação de brigadista florestal para combate às queimas e queimadas.

Em análise aos resultados e discussão dos dados coletados, verifica-se que o quantitativo de queimas, queimadas e incêndios florestais do Setor Lagoa da Ilha do município tocantinense de Lagoa da Confusão é decorrente da prática cultural de queima de limpeza, realizado tanto por homens quanto por mulheres, em uma etnia de maioria parda, em maioria superior a 30 anos de idade, com renda mensal de até $\mathrm{R} \$ 1.000,00$, escolaridade diversificada, residência no bairro de 2 a 10 anos, os quais todo ano observam queimas, e, cuja prática presente e/ou passada é verificada como dessemelhante.

\section{CONCLUSÕES}

O município tocantinense de Lagoa da Confusão é um dos maiores do estado em território, com população superior a 10.000 habitantes e possui base econômica na agropecuária de elevado fluxo financeiro, uma vez que a renda per capita ultrapassa os $\mathrm{R} \$ 39.000,00$, contudo a taxa de escolarização é a penúltima classificada no Estado do Tocantins.

Lagoa da Confusão apresenta o maior registro tocantinense no quantitativo de focos de calor ativo na série histórica de 2009 a 2018, este município integra o Protocolo do Fogo e realiza suas atuações preventivas e reativas ao combate às queimadas e aos incêndios florestais por meio de parcerias junto a organizações públicas e instituições privadas. Dentre os bairros do município, a Secretaria Municipal de Meio Ambiente e Segurança Pública aponta que o Setor Lagoa da Ilha é o ponto máximo de queima. 
Vale considerar que o município de Lagoa da Confusão apresenta o maior PIB Agropecuário tocantinense, mesmo com o maior índice estadual no histórico de queimas e o terceiro menor de taxa de escolarização, e por tais contradições se verificou a necessidade de uma pesquisa de campo no recorte territorial definido com aplicação de questionário a fim de compreender o comportamento populacional dos habitantes do Setor Lagoa da Ilha do município tocantinense de Lagoa da Confusão diante das queimas, queimadas e incêndios florestais. Este bairro se situa na área sudoeste do município, com lotes lindeiros abertos, a minoria das ruas com pavimentação asfáltica, presença larga de capim andropogon e vasta arborização nativa em zona urbana; os quais são elementos são propícios às queimas.

Diante de variáveis controversas, os pesquisadores vislumbraram a necessidade de aplicação da ferramenta de questionário em uma pesquisa de campo a fim de alcançar o objetivo proposto a esta pesquisa. Este questionário alcançou prévia aprovação do Comitê de Ética em Pesquisa em Seres Humanos da Universidade Federal do Tocantins, com financiamento do próprio pesquisador, consta de onze variáveis, das quais noves são aplicadas a esta pesquisa, e possui quatro critérios de exclusão. Neste instrumento de pesquisa para coleta de dados os participantes tiveram suas identidades preservadas, foram informados e assinaram a concordância do Termo de Consentimento Livre e Esclarecido para posterior cessão de respostas às questões diretas e de múltipla escolha do questionário.

O quantitativo de residências para a aplicação de um questionário teve por população as espécies de domicílio 'particular permanentemente ocupado' e 'particular permanentemente fechado', ao alcance numérico de 88, no qual todos foram localizados, contudo a aplicação do questionário ocorreu em todos de espécie ocupado e em pouco mais de $30 \%$ dos de espécie fechado; portanto, a amostragem de registro foi um quantitativo de quase $50 \%$, dentre os quais $13 / 43$ foram excluídos por residirem no Setor Lagoa da llha em período inferior a dois anos.

Após a etapa de coleta dos dados, os mesmos foram interpretados em quantitativo proporcional à amostragem de 30 respondentes válidos, por meio do qual se compreendeu que o comportamento populacional do recorte territorial está vinculado a uma cultura de queima de limpeza praticada por homens e mulheres, de maioria parda, com idade superior a 30 anos, renda mensal de até $\mathrm{R} \$ 1.000,00$, com escolaridade diversificada, residência de 2 a 10 anos no bairro, com observação constante de queimas e queimadas em todo ano, e, dissímil prática presente e/ou passada de queimas.

Nesta compreensão, conclui-se que o objetivo proposto para este estudo foi de caráter total, uma vez que o mesmo foi alcançado, pois o comportamento populacional do Setor Lagoa da llha do município tocantinense de Lagoa da Confusão foi compreendido, e a partir deste momento há a possibilidade de realização de novos estudos para as novas metodologias preventivas e as ações reativas no combate às queimas, às queimadas e aos incêndios florestais.

\section{REFERÊNCIAS}

BORGES SOBRINHO, C. J.; RAMOS JUNIOR, D. V.. As queimas e as queimadas no Tocantins: o município de maior registro da série histórica de focos de calor ativos. Revisa Ibero-
Americana de Ciências Ambientais, Aracaju, v.11, n.1, p.378-390, 2020a. DOI: http://doi.org/10.6008/CBPC21796858.2020.001.0034 
BORGES SOBRINHO, C. J.; RAMOS JUNIOR, D. V.. Práticas tranversais contra os incêndios florestais e as queimadas no Tocantins. Revista Flammae, São Luis, v.6, n.15, p.172, 2020b.

CNS. Conselho Nacional de Saúde. Resolução n. 466, de 12 de dezembro de 2012. 240 Reunião Ordinária, em 11 e 12 de dezembro de 2016. Brasília: CNS, 2012.

CNS. Conselho Nacional de Saúde. Resolução n. 510, de 07 de abril de 2016. 59 Reunião Extraordinária, em 06 e 07 de abril de 2016. Brasília: CNS, 2016.

CEPDEC. Coordenadria Estadual de Proteção e Defesa Civil Tocantins. Comitê do Fogo: histórico, membros e plano de ações. Oficio n. 219/2019/CEPDEC, de 29 de agosto de 2019. SGD 2019/09009/0008728. Palmas: CEPDEC, 2019.

CBMGO. Corpo de Bombeiros Militar do Estado de Goiás. Manual Operacional de Bombeiros: prevenção e combate a incêndios florestais. Goiânia: CBMGO, 2017.

IBGE. Instituto Brasileiro de Geografia e Estatística. Tabela 5938: Produto interno bruto a preços correntes, impostos, líquidos de subsídios, sobre produtos a preços correntes e valor adicionado bruto a preços correntes total e por atividade econômica, e respectivas participações Referência 2010-2015. Brasil: IBGE, 2017.

IBGE. Instituto Brasileiro de Geografia e Estatística. Lagoa da Consfusão. Brasília: IBGE, 2020a.

IBGE. Instituto Brasileiro de Geografia e Estatística. Quadro Espécie Habitação: Tocantins: Lagoa da Confusão: Setor Lagoa da Ilha. Brasil: IBGE, 2020b.
LAGOA DA CONFUSÃO. Prefeitura Municipal. A cidade. Lagoa da Confusão: DOE, 2018.

LAGOA DA CONFUSÃO. Prefeitura Municipal. Incêndios florestais e queimadas: ações preventivas e combate. Ofício n. 0558/2019: Secretaria Municipal de Meio Ambiente e Segurança Pública, de 18 de julho de 2019. Lagoa da Confusão: SEMASP, 2019.

SANTOS, L. A. C.. Utilização dos dados do Cadastro Ambiental Rural na análise de conflitos de uso do solo em Áreas de Preservação Permanente. Tecnia: Revista de Educação, Ciência e Tecnologia do IFG, Goiânia, v.3, n.1, 2018.

SEIA. Sistema Estadual de Informações Ambientais e Recursos Hídricos. Monitoramento Ambiental. Salvador: SEIA, 2020.

TOCANTINS. Secretaria do Planejamento e Orçamento. Indicadores socioeconômicos do Estado do Tocantins. Versão 2017. Palmas: SEPLAN, 2017.

TOCANTINS. Secretaria de Desenvolvimento Econômico, Ciência, tecnologia, Turismo e Cultura. Tocantins: História. Palmas: SEDEN, 2015.

TORRES, F. T. P.; LIMA, G. S.; COSTA, A. G.; FÉLIX, G. A.; SILVA JÚNIOR, M. R.. Perfil dos incêndios florestais em unidades conservaão brasileiras no periodo de 2008 a 2012. Revista Floresta, Curitiba, v.46, n.4, p.531-542 2016. DOI: http://doi.org/10.5380/rf.v46i3.44199

A CBPC - Companhia Brasileira de Produção Científica (CNPJ: 11.221.422/0001-03) detém os direitos materiais desta publicação. Os direitos referem-se à publicação do trabalho em qualquer parte do mundo, incluindo os direitos às renovações, expansões e disseminações da contribuição, bem como outros direitos subsidiários. Todos os trabalhos publicados eletronicamente poderão posteriormente ser publicados em coletâneas impressas sob coordenação da Sustenere Publishing, da Companhia Brasileira de Produção Científica e seus parceiros autorizados. Os (as) autores (as) preservam os direitos autorais, mas não têm permissão para a publicação da contribuição em outro meio, impresso ou digital, em português ou em tradução. 